\title{
Analysis of nutritional composition, antioxidant activity and callus induction of Oryza sativa cultivars Khumthan and Norprae
}

\author{
Natthiya Chaichana \\ Science Program, Faculty of Education, Chiang Rai Rajabhat University, Chiang Rai 57100 Thailand \\ e-mail: natthiya.cha@crru.ac.th \\ Received 2 Apr 2019 \\ Accepted 10 Oct 2019
}

\begin{abstract}
The purpose of this study was to investigate the nutritional composition, antioxidant activity and callus induction of Oryza sativa cultivars Khumthan and Norprae, which are the local rice cultivars in Chiang Saen district, Chiang Rai province, Thailand. Nutritional information was examined by AOAC method. It was found that fat, proteins, carbohydrates, crude fibre and ash composition of both rice cultivars were varied in the range of 2.56-2.91, 6.53-9.09, 71.87-76.36, 1.60-2.03, and 1.14-2.10\%, respectively. Furthermore, twelve kinds of minerals including N, P, K, Ca, $\mathrm{Mg}, \mathrm{Mn}, \mathrm{S}, \mathrm{B}, \mathrm{Na}, \mathrm{Fe}, \mathrm{Zn}$, and $\mathrm{Cu}$ were also detected in both cultivars. For antioxidant analysis, O. sativa cultivar Norprae had antioxidant activity of $19.39 \mu \mathrm{mol} \mathrm{TE} / \mathrm{g}$, while cultivar Khumthan had the lower value of antioxidant activity $(2.4 \mu \mathrm{mol} \mathrm{TE} / \mathrm{g})$. Callus induction of both cultivars was examined. The seeds were surface sterilized with 15\% Clorox for $10 \mathrm{~min}$. The sterilized seed embryos were transferred to MS (Murashige and Skoog, 1962) medium supplemented with 0, 0.5, 1.0, $2.0 \mathrm{mg} / 1$ 2,4-D (2,4-dichlorophenoxyacetic acid) or kinetin. The result revealed that MS medium supplemented with $0.5 \mathrm{mg} / 1$ 2,4-D provided the highest callus induction of cultivars Khumthan and Norprae with 1.344 and $1.385 \mathrm{~g}$ fresh weight, respectively.
\end{abstract}

KEYWORDS: Oryza sativa, antioxidant, 2,4-dichlorophenoxyacetic acid, nutrition, mineral

\section{INTRODUCTION}

Rice (Oryza sativa) is the most important natural resource for worldwide consumption. There are a lot of $O$. sativa cultivars distributed among various countries and each country has valuable local rice. It is a major source of nutrients, especially carbohydrates. Furthermore, it has antioxidant capacity and other medicinal properties ${ }^{1}$. There are several rice varieties worldwide with different characteristics and chemical compositions. For example, there are differences in the nutrient content (e.g., protein, amylose and fat acidity) between Vietnamese and Japanese rice cultivars ${ }^{2}$. The nutrient and chemical composition of local black rice species in Indonesia has great potential as functional food due to its nutraceutical properties and ability to reduce noncommunicable diseases ${ }^{3}$. Some varieties of African (NERICA) rice were analyzed, they contained moisture, ash, fibre, fat, proteins, and carbohydrates in the range of 8.2-9.8, 0.02-0.09, 0.3-0.5, 2.4 $5.7,5.9-13.0$, and $74.4-82.8 \%$, respectively. In addition, they contained iron $(30-69.3 \mathrm{mg} / \mathrm{kg}$ ), zinc $(2.4-10.4 \mathrm{mg} / \mathrm{kg})$, copper $(0.5-4.6 \mathrm{mg} / \mathrm{kg})$, calcium (43.4-146 mg/kg), and magnesium (85.5-
$368 \mathrm{mg} / \mathrm{kg})^{4}$. The mineral contents vary among rice varieties. The previous research revealed that brown rice provided an essential source of vitamins and minerals ${ }^{5}$. Antioxidant activity was also discovered in the rice extract. For example, in two Iranian rice varieties (Fajr and Tarem), DPPH free radicalscavenging activity was highest (93.91\%) at $50 \mathrm{mg} / 1$ concentration $^{6}$.

Regeneration by callus induction of the rice plant tissue culture was previously examined. Plant growth regulators used for callus induction were cytokinin and auxin, which played a role of callus development and differentiation. The callus induction of some selected basmati rice cultivars of Pakistan (O. sativa cv. Basmati 370, basmati 385, Super basmati and Shaheen basmati) were studied. The experiment showed that N6 media containing $5.0 \mathrm{~g} / \mathrm{l}$ agar and 2.0-2.5 mg/1 2,4-D provided the highest callus induction of $53.0-85.07 \%{ }^{7}$. The effect of synthetic auxin 2,4-D was optimized for callus induction of indica rice (O. sativa) cultivar ADT 43. Embryogenesis in callus cultures was achieved using LS medium supplemented with $2.5 \mathrm{mg} / 1$ 2,4$\mathrm{D}$ and $1.0 \mathrm{mg} / 1$ thiamine- $\mathrm{HCL}^{8}$. O. sativa culti- 

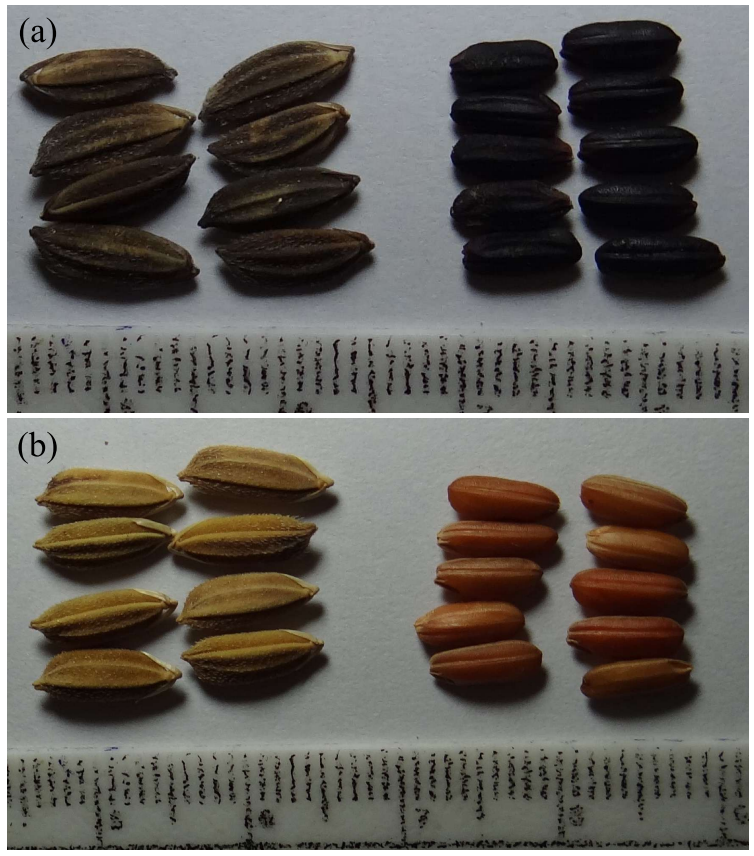

Fig. 1 Grains of O. sativa cultivars Khumthan (a) and Norprae (b).

vars Khumthan and Norprae are found in Chiang Sean district, Chiang Rai province, Thailand. Both cultivars have black and red grains, respectively (Fig. 1). The nutritional composition, antioxidant activity, as well as conservation method, were not investigated before. Hence this study aimed to study $O$. sativa cultivars Khumthan and Norprae in the aspects of nutritional information, antioxidant activity and callus induction for conservation and further development for valuable metabolites.

\section{MATERIALS AND METHODS}

\section{Nutritional and mineral information of $O$. sativa} cultivars Khumthan and Norprae

O. sativa cultivars Khumthan and Norprae were harvested from Chiang Sean district, Chiang Rai province. All of samples were dried, dehulled and weighted $(100 \mathrm{~g})$. Then, the proximate analysis of the dried seed was performed by the AOAC method for the composition of fat, protein, carbohydrate, crude fibre, and ash ${ }^{9}$. The total amounts of nitrogen $(\mathrm{N})$, phosphorus (P), boron (B), and sulfur ( $\mathrm{S}$ ) were measured by Kjedahl, Vanadomolybdate, Azomethine- $\mathrm{H}$ and $\mathrm{BaCl}_{2}$ method, respectively. Atomic Absorption Spectroscopy was used to quantify calcium (C), magnesium (Mg), iron $(\mathrm{Fe})$, manganese $(\mathrm{Mn})$, copper $(\mathrm{Cu})$, and zinc $(\mathrm{Zn})$.
Potassium (K) and sodium (Na) were quantified by Atomic Emission Spectroscopy. All treatments were performed in triplicate.

\section{Antioxidant activity of $O$. sativa cultivars Khumthan and Norprae}

The seeds of $O$. sativa cultivars Khumthan and Norprae were dried, dehulled, weighted (100 g), ground and extracted by methanol (Merck, HPLC grade, Germany). Then the sample solution was filtered and evaporated by a rotary vacuumevaporator. The crude extract was investigated for DPPH (2,2-diphenyl-1-picrylhydrazyl) radicalscavenging activity by the method slightly modified from Brand-Williams et al and Miliauskasa et al ${ }^{10,11}$. Three $\mathrm{ml}$ of DPPH solution were added and mixed with 77 (38 or 19 in additional assays) ml methanol extract solution in microcuvettes (ratio of extract to DPPH was approximately $3: 1,1.5: 1,0.75: 1$ ). The absorbance $(515 \mathrm{~nm})$ was recorded by a UV/visible spectrophotometer after being kept in the dark for $15 \mathrm{~min}$ at room temperature. The experiment was performed in triplicate. Trolox was used as a standard antioxidant. The results were expressed in $\mu \mathrm{mol} \mathrm{TE} / \mathrm{g}$.

\section{Callus induction of $O$. sativa cultivars Khumthan and Norprae}

O. sativa cultivars Khumthan and Norprae seeds were surface sterilized with $15 \%$ Clorox for $10 \mathrm{~min}$ followed by three times washing with sterile distilled water. The sterilized seed embryos were cut and transferred to $\mathrm{MS}^{12}$ medium supplemented with $0,0.5,1.0,2.0 \mathrm{mg} / 1$ 2,4-D or kinetin for 15 replicates. Sucrose at $30 \mathrm{~g} / \mathrm{l}$ was added to the medium and the $\mathrm{pH}$ was adjusted to 5.8 with $1 \mathrm{M}$ $\mathrm{KOH}$. Agar at $7 \mathrm{~g} / \mathrm{l}$ was melted and added for solidification. The cultures were placed at $25 \pm 2{ }^{\circ} \mathrm{C}$ under $16 \mathrm{~h} / \mathrm{d}$ photoperiod for 4 weeks. Callus induction (\%) and callus fresh weight (g) were recorded.

\section{Statistical analysis}

The statistical significance of nutritional, mineral information and antioxidant activity were determined by analysis of an independent sample $t$-test. For callus induction, statistical significance was determined by ANOVA with an adjustment for multiple comparisons with Turkey's test. Values are expressed in triplicate by means \pm standard deviation. Values with different superscripts are significantly different $(p \leqslant 0.05)$. 
Table 1 Nutrient compositions of $O$. sativa cultivars Khumthan and Norprae seeds.

\begin{tabular}{lrr}
\hline Nutrient composition & \multicolumn{1}{c}{ Khumthan } & \multicolumn{1}{c}{ Norprae } \\
\hline Fat & $2.91 \pm 0.04^{\mathrm{a}}$ & $2.56 \pm 0.06^{\mathrm{b}}$ \\
Protein & $9.09 \pm 0.03^{\mathrm{a}}$ & $6.53 \pm 0.07^{\mathrm{b}}$ \\
Carbohydrate & $71.87 \pm 0.09^{\mathrm{b}}$ & $76.36 \pm 0.12^{\mathrm{a}}$ \\
Crude fibre & $2.03 \pm 0.04^{\mathrm{a}}$ & $1.60 \pm 0.05^{\mathrm{b}}$ \\
Ash & $2.10 \pm 0.05^{\mathrm{a}}$ & $1.14 \pm 0.01^{\mathrm{b}}$ \\
\hline
\end{tabular}

Values are means \pm standard deviation of triplicate determinations. Values in the same row with different superscripts are significantly different $(p \leqslant 0.05)$.

\section{RESULTS AND DISCUSSION}

\section{Nutritional and mineral information of $O$. sativa} cultivars Khumthan and Norprae

The nutrient compositions of $O$. sativa cultivars Khumthan and Norprae rice are described in Table 1 . The result revealed that $O$. sativa cultivar Khumthan had higher amounts of fat, protein, crude fibre, and ash $(2.91,9.09,2.03$, and $2.10 \%$ ) than $O$. sativa cultivar Norprae. On the other hand, O. sativa cultivar Norprae had a higher content of carbohydrates $(76.36 \%)$ than $O$. sativa cultivar Khumthan. Other rice varieties, such as red and white rice cultivars procured from the local market of Uttarakhand in India, contained 70.16 and $78.34 \%$, respectively ${ }^{13}$. O. sativa cultivars Khumthan (black coloured rice) contained high protein content $(9.09 \%)$ as well. Similarly with the previous experiment of CIC Black rice, the local rice variety from Sri Lanka, which was composed of $10.45 \%$ proteins ${ }^{14}$ while $O$. sativa cultivar Norprae (red coloured rice) had 6.53\%. There were many coloured rice cultivars that contained the amount of protein similar to $O$. sativa cultivars Khumthan. For example, crude protein content was in the range of $5.43-13.83 \%$ in brown rice cultivars of Assam, India ${ }^{15}$. O. sativa cultivars Khumthan and Norprae was found to have a higher level of protein than some rice varieties grown in Ebonyi state of Nigeria such as Sipi (1.58\%), E4077 (4.00\%), and Awilo $(4.82 \%)^{16}$. Furthermore, O. sativa cultivar Khumthan could produce more ash content than two varieties of pigmented rice from Thailand (Thai black rice Khao Nim and Thai Jasmine red rice) and one variety of wild rice (Zizania aquatica) from Canada. All of the rice provided ash content in the range between 1.40 and $1.61 \%{ }^{17}$.

The results of mineral analysis of $O$. sativa cultivars Khumthan and Norprae are shown in Table 2. Mineral compositions ( $\mathrm{N}, \mathrm{P}, \mathrm{Ca}, \mathrm{Mg}$, and $\mathrm{Zn}$ ) of
Table 2 Mineral compositions of $O$. sativa cultivars Khumthan and Norprae seeds.

\begin{tabular}{lcc}
\hline Mineral composition & Khumthan & Norprae \\
\hline $\mathrm{N}(\%)$ & $1.42 \pm 0.05^{\mathrm{a}}$ & $1.29 \pm 0.01^{\mathrm{b}}$ \\
$\mathrm{P}(\%)$ & $0.41 \pm 0.02^{\mathrm{a}}$ & $0.36 \pm 0.02^{\mathrm{b}}$ \\
K (\%) & $0.38 \pm 0.03^{\mathrm{a}}$ & $0.32 \pm 0.04^{\mathrm{a}}$ \\
$\mathrm{Ca}(\%)$ & $0.27 \pm 0.01^{\mathrm{a}}$ & $0.20 \pm 0.03^{\mathrm{b}}$ \\
Mg (\%) & $0.09 \pm 0.005^{\mathrm{a}}$ & $0.07 \pm 0.004^{\mathrm{b}}$ \\
Mn (mg/kg DW) & $29.75 \pm 0.50^{\mathrm{a}}$ & $28.75 \pm 0.15^{\mathrm{a}}$ \\
$\mathrm{S}(\%)$ & $0.09 \pm 0.008^{\mathrm{a}}$ & $0.08 \pm 0.002^{\mathrm{a}}$ \\
B (mg/kg DW) & $2.77 \pm 0.04^{\mathrm{b}}$ & $3.26 \pm 0.06^{\mathrm{a}}$ \\
Na (mg/kg DW) & $55.52 \pm 0.12^{\mathrm{b}}$ & $59.04 \pm 1.20^{\mathrm{a}}$ \\
Fe (mg/kg DW) & $10.66 \pm 0.08^{\mathrm{b}}$ & $16.95 \pm 0.15^{\mathrm{a}}$ \\
Zn (mg/kg DW) & $47.74 \pm 0.14^{\mathrm{a}}$ & $38.29 \pm 0.23^{\mathrm{b}}$ \\
Cu (mg/kg DW) & $2.62 \pm 0.03^{\mathrm{b}}$ & $2.92 \pm 0.06^{\mathrm{a}}$ \\
\hline
\end{tabular}

DW $=$ dry weight.

cultivar Khumthan were higher than cultivar Norprae. While, other mineral compositions, including $\mathrm{Na}, \mathrm{Fe}$, and $\mathrm{Cu}$, of cultivar Khumthan were less than those of cultivar Norprae. However, for some minerals (K, Mn, and $\mathrm{S}$ ), there was no notable different in quantity. Similarly with previous research, the study presented that black rice had higher contents of $\mathrm{Zn}, \mathrm{Ca}$, and $\mathrm{Mg}$ than red rice ${ }^{18}$. The levels of mineral compositions of $O$. sativa cultivars Khumthan and Norprae were higher than other rice varieties. For example, the content level of Zn (3.829-4.774 mg\%) was higher than some pigmented hill rice cultivars of Assam from India (3.42$4.28 \mathrm{mg} \%)^{19}$. O. sativa cultivars Khumthan and Norprae also had higher mineral levels in comparison to other rice varieties. The contents of $\mathrm{Zn}, \mathrm{Mn}$, and $\mathrm{Cu}$ of Irri-6, Irri-9, Sarshar, and DR-83 Pakistani rice varieties were ranged from 1.44-2.97 mg\%, $1.57-2.33 \mathrm{mg} \%$, and $0.58-0.92 \mathrm{mg} \%{ }^{20}$. In addition, new rice varieties in Ghana were found to contain P, Ca, and K levels of 26.3-51.0 mg\%, 5.55$9.53 \mathrm{mg} \%$, and $48.2-76.2 \mathrm{mg} \%$, respectively ${ }^{21}$. From the mineral analysis of $O$. sativa varieties in Nigeria $^{22}$, the result revealed that the mineral contents were in the range of $113.07-118.75 \mathrm{mg} \%$ for K, $27.96-31.31 \mathrm{mg} \%$ for Ca, $24.36-29.81 \mathrm{mg} \%$ for $\mathrm{Mn}, 113.91-121.34 \mathrm{mg} \%$ for P, $1.43-2.75 \mathrm{mg} \%$ for Zn, $1.18-2.00 \mathrm{mg} \%$ for $\mathrm{Mn}$, and $0.14-0.32 \mathrm{mg} \%$ for $\mathrm{Cu}$. The nutritional composition could be affected differently between varieties, due to the nature of the soil, environmental conditions, and fertilizers used $^{23}$. The nutritional and medicinal values of some rice varieties varied among different areas and colours of rice. The coloured rice varieties were comparatively identified as more nutritious ${ }^{24}$. The 
Table 3 Antioxidant activity of $O$. sativa cultivars Khumthan and Norprae seeds.

\begin{tabular}{lc}
\hline O. sativa cultivar & DPPH $(\mu \mathrm{mol} \mathrm{TE} / g)$ \\
\hline Khumthan & $2.40 \pm 0.06^{\mathrm{b}}$ \\
Norprae & $19.39 \pm 0.07^{\mathrm{a}}$ \\
\hline
\end{tabular}

study showed that $O$. sativa cultivars Khumthan and Norprae could be functional foods in the future as they contain both essential nutrients and minerals.

\section{Antioxidant activity of $O$. sativa cultivars Khumthan and Norprae seed extract}

Antioxidant activity of $O$. sativa cultivars Khumthan and Norprae were quantified and the result is presented in Table 3 . It was found that $O$. sativa cultivar Norprae had higher antioxidant activity than $O$. sativa cultivar Khumthan. Antioxidative properties of different rice varieties of pigmented rice in northern Thailand (Chiang Mai black rice, Mali red rice and Suphanburi-1 brown rice) were previously reported. The results revealed that they highly produced phytochemicals, anthocyanin, and free radical scavenging compounds ${ }^{25}$. Furthermore, these pigmented rice varieties had a higher antioxidant efficiency than the white rice. The contents of phenolic compounds, total flavonoid and antioxidants were also detected in a higher quantity than those of non-pigmented rice ${ }^{26,27}$. Bioactive compounds and antioxidative activities of six coloured rice varieties were measured. The result revealed that the extract contained phenolic compounds, flavonoids, proanthocyanidins, and anthocyanins. Proanthocyanidins could only be detected in red rice, whereas anthocyanins could be detected in black rice. The antioxidant activity of red rice was higher compared to black rice ${ }^{28}$. In addition, antioxidant properties of pigmented rice were related to total soluble phenolic compounds found in each rice variety ${ }^{29}$. Hence it could be concluded that the pigmented rice (especially $O$. sativa cultivars Norprae) were composed of bioactive compounds that attributed to the antioxidant activity. Hence they became valuable natural sources of nutritional foods with antioxidant activity and potentials for other medicinal properties that could lead to development for useful functional products in the future.

\section{Callus induction of $O$. sativa cultivars Khumthan and Norprae}

The callus induction of $O$. sativa cultivars Khumthan and Norprae is described in Tables 4 and 5. The
Table 4 Callus induction of $O$. sativa cultivar Khumthan.

\begin{tabular}{lcc}
\hline Medium & Induction (\%) & Fresh weight $(\mathrm{g})$ \\
\hline MS & 0 & $0^{\mathrm{c}}$ \\
MS+0.5 mg/1 2,4-D & 100 & $1.344 \pm 0.091^{\mathrm{a}}$ \\
MS+1.0 mg/1 2,4-D & 100 & $0.121 \pm 0.017^{\mathrm{b}}$ \\
MS+2.0 mg/1 2,4-D & 100 & $0.113 \pm 0.010^{\mathrm{b}}$ \\
MS+0.5 mg/l Kinetin & 0 & $0^{\mathrm{c}}$ \\
MS+1.0 mg/l Kinetin & 0 & $0^{\mathrm{c}}$ \\
MS+2.0 mg/l Kinetin & 0 & $0^{\mathrm{c}}$ \\
\hline
\end{tabular}

Table 5 Callus induction of $O$. sativa cultivar Norprae.

\begin{tabular}{lcc}
\hline Medium & Induction (\%) & Fresh weight (g) \\
\hline MS & 0 & $0^{\mathrm{c}}$ \\
MS+0.5 mg/1 2,4-D & 93.33 & $1.385 \pm 0.058^{\mathrm{a}}$ \\
MS+1.0 mg/1 2,4-D & 60.00 & $0.452 \pm 0.040^{\mathrm{b}}$ \\
MS+2.0 mg/1 2,4-D & 54.00 & $0.384 \pm 0.018^{\mathrm{b}}$ \\
MS+0.5 mg/l Kinetin & 0 & $0^{\mathrm{c}}$ \\
MS+1.0 mg/l Kinetin & 0 & $0^{\mathrm{c}}$ \\
MS+2.0 mg/l Kinetin & 0 & $0^{\mathrm{c}}$ \\
\hline
\end{tabular}

results showed that MS medium supplemented with 2,4-D could induce callus formation and MS medium supplemented with $0.5 \mathrm{mg} / 1$ 2,4-D was most efficient for callus induction (1.344 and $1.385 \mathrm{~g}$ fresh weight, respectively). MS medium without plant growth regulator and MS medium supplemented with kinetin could not induce callus formation. Callus induction of rice was induced by 2,4-D. From the callus induction of Malaysian rice (O. sativa cv. Panderas), callus induction (90\%) could be obtained using the medium supplemented with 2,4-D and NAA ${ }^{30}$. Furthermore, 2,4-D also in-
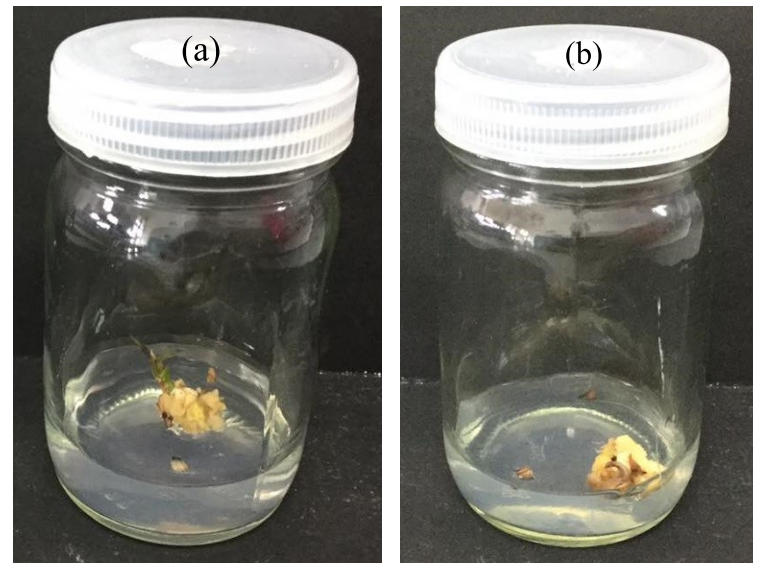

Fig. 2 Callus proliferation of $O$. sativa cultivars Khumthan (a) and Norprae (b). 
duced callus formation of O. sativa variety PAU 201 . It was found that embryogenic calli could be derived from MS medium containing $560 \mathrm{mg} / 1$ proline and 1.5-3.5 mg/1 2,4-D and 0.5-1.5 mg/1 kinetin ${ }^{31}$. In addition, callus induction of Thai rice $(O$. sativa $\mathrm{cv}$. Khao Daw Mali 105) was investigated. The result presented that modified MS medium supplemented with $2 \mathrm{mg} / 1$ 2,4-D, $10 \mathrm{mM}$ proline and 3\% sucrose exhibited callus proliferation ${ }^{32}$ (Fig. 2).

Multiple callus induction of $O$. sativa cultivar Norprae was performed by MS medium supplemented with $0.5 \mathrm{mg} / 1$ 2,4-D treatment. The callus was extracted and quantified for antioxidant activity. The result revealed that the callus exhibited DPPH radical-scavenging activity of $182.18 \mu \mathrm{mol}$ $\mathrm{TE} / \mathrm{g}$, more than that produced from the seeds. The rice callus (O. sativa) with supplemented exogenous elicitors could enhance enzymatic antioxidant activity ${ }^{33}$. The callus extraction for valuable compounds has also been investigated in many plant species. In vitro callus cultures of Hildegardia populifolia presented the highest antioxidant activity of $3077.98 \mu \mathrm{mol} \mathrm{TE} / \mathrm{g}$ extract via internode derived callus ${ }^{34}$. Antioxidant activity estimation from callus culture was also determined in several medicinal plants, e.g., Gynura procumbens ${ }^{35}$ and Arachis hypogaea $^{36}$. Rice callus could be further studied to investigate rapid production of beneficial compounds across elicitor supplementation culture. Furthermore, it has the potential use in rice breeding and genetic improvement under various techniques.

\section{CONCLUSION}

O. sativa cultivars Khumthan (black) and Norprae (red) were found to be composed of nutritional information (fat, proteins, carbohydrates, crude fibre and ash) and minerals (N, P, K, Ca, Mg, Mn, S, $\mathrm{B}, \mathrm{Na}, \mathrm{Fe}, \mathrm{Zn}$, and $\mathrm{Cu}$ ). The antioxidant activity was detected in the range of 2.4-19.39 $\mu \mathrm{mol}$ $\mathrm{TE} / \mathrm{g}$. The highest callus induction was obtained in MS medium containing $0.5 \mathrm{mg} / 1$ 2,4-D (1.344 and $1.385 \mathrm{~g}$ fresh weight for cultivars Khumthan and Norprae, respectively).

Acknowledgements: I gratefully acknowledge the support from the Research and Development Institute, Chiang Rai Rajabhat University, Chiang Rai, Thailand and the Institute of Biodiversity and Environment for Local and Asean Development, Chiang Rai Rajabhat University.

\section{REFERENCES}

1. Chaudhari PR, Tamrakar N, Singh L, Tandon A, Sharma D (2018) Rice nutritional and medicinal properties: A review article. J Pharmacogn Phytochem 7, 150-156.

2. Tran UT, Okadome H, Murata M, Homma S, Ohtsubo K (2001) Comparison of Vietnamese and Japanese rice cultivars in terms of physicochemical properties. Food Sci Technol Res 7, 323-330.

3. Pratiwi R, Purwestri YA (2017) Black rice as a functional food in Indonesia. Funct Food Health Dis 7, 182-194.

4. Olusegun OI, Grace FO, Sunday FO, Kayode S, Adeniyi AS (2018) Nutrient content and in-vitro starch hydrolysis of some varieties of Nerica rice. $J$ Food Studies 7, 68-82.

5. Tripathy SK, Dash M, Behera SK, Ithape DM, Maharana M (2017) Nutrient rich quality rice-a journey to healthy life. Adv Plants Agric Res 7, 364-367.

6. Araba F, Alemzadeh I, Maghsoudi V (2011) Determination of antioxidant component and activity of rice bran extract. Sci Iran 18, 1402-1406.

7. Mehmood K, Arshad M, Ali S, Qayyum M, Ali GM (2016) Comparative study of tissue culture response of some selected basmati rice cultivars of Pakistan. $J$ Rural Dev Agric 1, 30-38.

8. Karthikeyan A, Pandian STK, Ramesh M (2009) High frequency plant regeneration from embryogenic callus of a popular indica rice (Oryza sativa L.). Physiol Mol Biol Plants 15, 371-375.

9. Association of Official Analytical Chemists (2000) Official Methods of Analysis of AOAC International, AOAC, Gaithersburg, USA.

10. Brand-Williams W, Cuvelier ME, Berset C (1995) Use of a free radical method to evaluate antioxidant activity. LWT Food Sci Technol 28, 25-30.

11. Miliauskasa G, Venskutonisa PR, Beek TA (2004) Screening of radical scavenging activity of some medicinal and aromatic plant extracts. Food Chem 85, 231-237.

12. Murashige T, Skoog F (1962) A revised medium for rapid growth and bio assays with tobacco tissue cultures. Physiol Plant 15, 473-497.

13. Raghuvanshi R, Dutta A, Tewari G, Suri S (2017) Qualitative characteristics of red rice and white rice procured from local market of Uttarakhand: A comparative study. J Rice Res 10, 49-53.

14. Samaranayake MDW, Abeysekera WKSM, Liyanage SL, Premakumara GAS, Abeysekera WPKM, Ratnasooriya WD, Abeysiriwardena DSZ (2018) Physicochemical and nutritional properties of selected pigmented and white long grain rice varieties of Sri Lanka at different polishing rates. Res J Chem Sci 8, 29-35.

15. Mudoi T, Das P (2018) Nutritional composition of traditional colored rice cultivars of Assam, India. Bull Env Pharmacol Life Sci 7, 10-14.

16. Oko AO, Ubi BE, Efisue AA, Dambaba N (2012) Comparative analysis of the chemical nutrient composition of selected local and newly introduced rice 
varieties grown in Ebonyi state of Nigeria. Int $J$ Agric Forestry 2, 16-23.

17. Melini V, Acquistucci R (2017) Health-promoting compounds in pigmented Thai and wild rice. Foods 6, ID 9, 1-13.

18. Meng F, Wei Y, Yang X (2005) Iron content and bioavailability in rice. $J$ Trace Elements Med Biol 18, 333-338.

19. Pathak K, Rahman SW, Bhagawati S, Gogoi B (2017) Assessment of nutritive and antioxidant properties of some indigenous pigmented hill rice (Oryza sativa L.) cultivars of Assam. Indian J Agric Res 51, 214-220.

20. Anjum FM, Pasha I, Anwar Bugti M, Butt MS (2007) Mineral composition of different rice varieties and their milling fractions. Pak J Agri Sci 44, 332-336.

21. Amissah JGN, Ellis WO, Oduro I, Manful JT (2003) Nutrient composition of bran from new rice varieties under study in Ghana. Food Control 14, 21-24.

22. Thomas AO, Olayinka A, Kayode A (2016) Comparative study of nutrient composition and retention of raw and cooked imported and local rice (Oryza sativa) varieties. British J Applied Sci Technol 16, 1-9.

23. Juliano BO, Albano EL, Cagampang GB (1964) Variability in protein content, amylose content and alkali digestibility of rice varieties in Asia. Philipp Agric 48, 234-241.

24. Rahman S, Sharma MP, Sahai S (2006) Nutritional and medicinal values of some indigenous rice varieties. Indian J Tradit Knowl 5, 454-458.

25. Pengkumsri N, Chaiyasut C, Saenjum C, Sirilun S (2015) Physicochemical and antioxidative properties of black, brown and red rice varieties of northern Thailand. Food Sci Technol 35, 331-338.

26. Muntana N, Prasong S (2010) Study on total phenolic contents and their antioxidant activities of Thai white, red and black rice bran extracts. Pak J Biol Sci 13, 170-174.

27. Vichapong J, Sookserm M, Srijesdaruk V, Swatsitang P, Srijaranai S (2010) High performance liquid chromatographic analysis of phenolic compounds and their antioxidant activities in rice varieties. LWT Food
Sci Technol 43, 1325-1330.

28. Huang YP, Lai HM (2016) Bioactive compounds and antioxidative activity of colored rice bran. $J$ Food Drug Analyst 24, 564-574.

29. Walter M, Marchesan E, Massoni PFS, Silva LP, Sartori GMS, Ferreira RB (2013) Antioxidant properties of rice grains with light brown, red and black pericarp colors and the effect of processing. Food Res Int 50, 698-703.

30. Din ARJM, Ahmad FI, Wagiran A, Samad AA, Rahmat Z, Sarmidi MR (2016) Improvement of efficient in vitro regeneration potential of mature callus induced from Malaysian upland rice seed (Oryza sativa cv. Panderas). Saudi J Biol Sci 23, 69-77.

31. Wani SH, Sanghera GS, Gosal SS (2011) An efficient and reproducible method for regeneration of whole plants from mature seeds of a high yielding Indica rice (Oryza sativa L.) variety PAU 201. New Biotechnol 28, 418-422.

32. Sangduen N, Klamsomboon P (2001) Histological and scanning electron observations on embryogenic and non-embryogenic calli of aromatic Thai rice (Oryza sativa L. cv. Khao Daw Mali 105). Kasetsart J Nat Sci 35, 427-432.

33. Alhasnawi AN, Mohd Zain CRC, Kadhimi AA, Isahak A, Mohamad A, Yusoff WMW (2017) Accumulation of antioxidants in rice callus (Oryza sativa L.) induced by $\beta$-glucan and salt stress. Australian J Crop Sci 11, 118-125.

34. Saradha M, Ranjitham P, Paulsamy S (2014) Evaluation of in vitro antioxidant properties of callus cultures of an endangered medicinal tree species, Hildegardia populifolia (Roxb.) Schott \& Endl. Int $J$ Pharm Sci Res 5, 839-848.

35. Krishnan V, Ahmad S, Mahmood M (2015) Antioxidant potential in different parts and callus of Gynura procumbens and different parts of Gynura bicolor. BioMed Res Int 2015, ID 147909, 1-7.

36. Vichit W, Saewan N (2019) In vitro antioxidant activities and cytotoxicity of peanut callus extract. Food App Biosci J 7, 142-151. 